\title{
Estudo Etnobotânico de Plantas Medicinais Utilizadas por alguns Moradores de Três Comunidades Rurais do Município de Cabaceiras do Paraguaçu/Bahia
}

\author{
Eliete Serra Rodrigues ${ }^{1}$, Noelma Miranda de Brito ${ }^{2}$ \& Vania Jesus Santos de Oliveira ${ }^{1}$
}

Recebido em 30/04/2020 - Aceito em 19/08/2020

1 Faculdade Maria Milza/FAMAM em Governador Mangabeira/BA. <ellirodrigues@live.com, vania79vr@yahoo.com.br>.

2 Faculdade Maria Milza/FAMAM em Governador Mangabeira/BA, Centro Territorial de Educação Profissional Recôncavo II Alberto Torres em Cruz das Almas/BA. <britonoelma@yahoo.com.br>.

\begin{abstract}
RESUMO - As pesquisas etnobotânicas envolvem levantamentos nas sociedades tradicionais sobre o uso dos vegetais na farmacopeia caseira, bem como questões culturais e econômicas da população, além das interações do homem com o meio ambiente. A Etnobotânica é o estudo do conhecimento da flora de uma região, que se preocupa com os sujeitos e com os seus saberes, reúne informações dos que mantiveram relações com os vegetais e com elementos culturais de um povo. Objetivouse realizar um estudo etnobotânico de plantas medicinais utilizadas em três comunidades rurais do município de Cabaceiras do Paraguaçu/BA. Foram aplicados 286 questionários aos membros das comunidades em suas residências. Para a análise dos dados, empregou-se a frequência relativa. Os participantes foram investigados quanto ao perfil socioeconômico e ao uso das plantas medicinais. Foram identificadas 45 espécies medicinais pertencentes a 25 famílias botânicas. As famílias Lamiaceae e Asteraceae foram as duas famílias botânicas mais representativas no estudo etnobotânico. A família Lamiaceae foi a mais representativa em número de espécies utilizadas como medicinais, $e$ as espécies mais citadas foram capim santo (Cymbopogon citratus Stapf.), erva cidreira (Lippia alba L.), boldo (Plectranthus barbatus Andrews) e hortelã (Mentha spicata L.). As plantas são adquiridas nos quintais das casas, usadas na forma de chá ou infuso. As folhas foram as partes da planta mais utilizadas. Evidenciou-se a importância da realização de estudos etnobotânicos como forma de resgatar e evitar a perda dos saberes tradicionais das comunidades de Jacarezinho, Nova Aparecida e Pé de Serra, e a conservação de espécies medicinais da flora da região.
\end{abstract}

Palavras-chave: Medicina popular; fitoterapia; conhecimento tradicional.

\section{Ethnobotanical Study of Medicinal Plants Used by some Residents of Three Rural Communities in the Municipality of Cabaceiras do Paraguaçu/Bahia}

ABSTRACT - Research on ethnobotany involves surveys in traditional societies about the use of vegetables in the home pharmacopoeia, as well as cultural and economic issues of the population, as well as man's interactions with the environment. Ethnobotany it is a study of the knowledge of the flora of a region, which is concerned with the subjects and their knowledge, gathers information from primitive peoples who, directly or indirectly, maintained relations with plants and with cultural elements of a people. The objective was to conduct an ethnobotanical study of medicinal plants used in three rural communities in the municipality of Cabaceiras do Paraguaçu/BA. Two hundred eightysix questionnaires were applied to community members in their homes. For the analysis of the data, the relative frequency was used. Participants were investigated for the socioeconomic profile and use of medicinal plants. Forty five medicinal species belonging to 25 botanical families were identified. The Lamiaceae and Asteraceae families were the two most representative botanical families in the ethnobotanical study. The Lamiaceae family was the most representative in number of species used as medicinal and the most cited species of bee balm (Lippia alba L.), capim santo (Cymbopogon citratus Stapf.), fennel (Foeniculum vulgare Mill), boldo (Plectranthus barbatus Andrews) and mint (Mentha spicata L.) were the medicinal species most reported by the interviewees. The plants are purchased in the backyards of the houses, used in the form of tea or infusion. The leaves were the parts of the plant 
most used. Thus, it became evident the importance of conducting ethnobotanical studies, as a way to rescue and prevent the loss of traditional knowledge from the communities of Jacarezinho, Nova Aparecida and Pé de Serra and the conservation of medicinal species of the region's flora.

Keywords: Popular medicine; phytotherapy; traditional knowledge.

\title{
Estudio Etnobotánico de Plantas Medicinales Utilizadas por algunos Residentes de Tres Comunidades Rurales en el Municipio de Cabaceiras do Paraguaçu/Bahia
}

\begin{abstract}
RESUMEN - La investigación sobre etnobotánica involucra encuestas en sociedades tradicionales sobre el uso de vegetales en la farmacopea casera, así como también sobre cuestiones culturales y económicas de la población, además de las interacciones humanas con el medio ambiente. La etnobotánica ya que es un estudio del conocimiento de la flora de una región, que se ocupa de los sujetos y sus conocimientos, recopila información de pueblos primitivos que, directa o indirectamente, mantuvieron relaciones con las plantas y con elementos culturales de un pueblo. El objetivo fue realizar un estudio etnobotánico de plantas medicinales utilizadas en tres comunidades rurales del municipio de Cabaceiras do Paraguaçu/BA. Se aplicaron 286 cuestionarios a miembros de la comunidad en sus hogares. Para el análisis de los datos se utilizó la frecuencia relativa. Los participantes fueron investigados por el perfil socioeconómico y el uso de plantas medicinales. Se identificaron 45 especies medicinales pertenecientes a 25 familias botánicas. Las familias Lamiaceae y Asteraceae fueron las dos familias botánicas más representativas en el estudio etnobotánico. La familia Lamiaceae fue la más representativa en número de especies utilizadas como medicinales y las especies más citadas de limoncillo (Lippia alba L.), el capim santo (Cymbopogon citratus Stapf.), el hinojo (Foeniculum vulgare Mill), el arándano (Plectranthus barbatus Andrews) y la menta (Mentha spicata L.) fueron las especies medicinales más reportadas por los entrevistados. Las plantas se compran en los patios traseros de las casas, se utilizan en forma de té o infusión. Las hojas fueron las partes de la planta más utilizadas. Así, la importancia de realizar estudios etnobotánicos era evidente, como una forma de rescatar y prevenir la pérdida de conocimiento tradicional de las comunidades de Jacarezinho, Nova Aparecida y Pé de Serra y la conservación de especies medicinales de la flora de la región.
\end{abstract}

Palabras clave: Medicina popular; fitoterapia; conocimientos tradicionales.

\section{Introdução}

As plantas medicinais são definidas como toda e qualquer planta que possui substâncias com propriedades terapêuticas, seja em partes específicas ou como todo, que é utilizada pelo homem com propósitos de cura (Brasil, 2010). A Etnobotânica abrange o estudo das plantas medicinais, pois é um estudo sobre o conhecimento da flora de uma região, que se preocupa com os sujeitos e os seus saberes, reúne informações dos povos primitivos que mantiveram relações com os vegetais e com elementos culturais de um povo (Siqueira \& Pereira, 2014).

Os estudos etnobotânicos são importantes, uma vez que permitem avaliar de que maneira os habitantes reúnem conhecimentos trazidos de seus locais de origem e como são transmitidos para as novas gerações (Cavalcante \& Silva, 2014). Esses estudos viabilizam o reconhecimento do saber local e buscam encontrar estratégias que permitam colocar em diálogo os saberes científicos com os saberes locais culturalmente arraigados, que contribuem com o desenvolvimento de práticas sustentáveis de uso e gerenciamento de recursos naturais (Strachulski \& Floriani, 2013). $\mathrm{E}$, assim, consolidam-se como uma ferramenta de pesquisa que favorece a interação do homem com a grande diversidade vegetal (Franco et al., 2011). A Organização Mundial da Saúde (OMS) reconhece o valor dos trabalhos etnobotânicos, que mostram a relevância das espécies medicinais de uso tradicional nas diferentes enfermidades, estimulando as comunidades a identificarem suas próprias tradições em relação às terapias, explorando práticas seguras e eficazes para posterior utilização em cuidados primários de saúde (Scardelato et al., 2013).

O estudo das plantas medicinais é um dos ramos de mais destaque da Etnobotânica, que pode funcionar como suporte eficiente sobre as práticas e utilização sustentável dos vegetais, conservando 
os elementos (sociais, culturais, abióticos e bióticos) das comunidades humanas. A análise e preservação desses saberes são imprescindíveis aos estudos etnobotânicos (Staniski et al., 2014; Silva et al., 2015), que cada vez mais estão desaparecendo nas comunidades rurais e urbanas (Do Ó et al., 2016). O elevado interesse da população brasileira no uso das plantas medicinais resultou, em 2009, na publicação de uma lista com 71 espécies medicinais, divulgada pelo Ministério da Saúde, contemplando a Relação Nacional de Plantas Medicinais de Interesse ao Sistema Único de Saúde (RENISUS), visando ao desenvolvimento de medicamentos fitoterápicos e ao uso no Sistema Único de Saúde (SUS) (Muniz et al., 2012).

Com base nesse contexto, o resgate e a valorização dos saberes tradicionais da flora medicinal das comunidades rurais e sua articulação com o conhecimento científico são muito importantes, o que justifica a realização deste trabalho, cujo objetivo foi realizar um estudo etnobotânico de plantas medicinais utilizadas em três comunidades rurais do município de Cabaceiras do Paraguaçu/BA.

\section{Material e Métodos}

\section{Descrições da população de estudo}

O estudo foi realizado em três comunidades, Pé de Serra, Nova Aparecida e Jacarezinho, localizadas na zona rural do município de Cabaceiras do Paraguaçu, localizada a $160 \mathrm{~km}$ de distância de Salvador, Bahia (Figura 1). A população estimada em 2016 foi de 19.199 habitantes, sendo a sua maior concentração populacional na zona rural. $\mathrm{O}$ município de Cabaceiras do Paraguaçu apresenta vegetação de caatinga, em transição com a zona da mata, característica de Mata Atlântica, com área de vegetação mais densa, de árvores com potencial econômico e de terra fértil (IBGE, 2016).

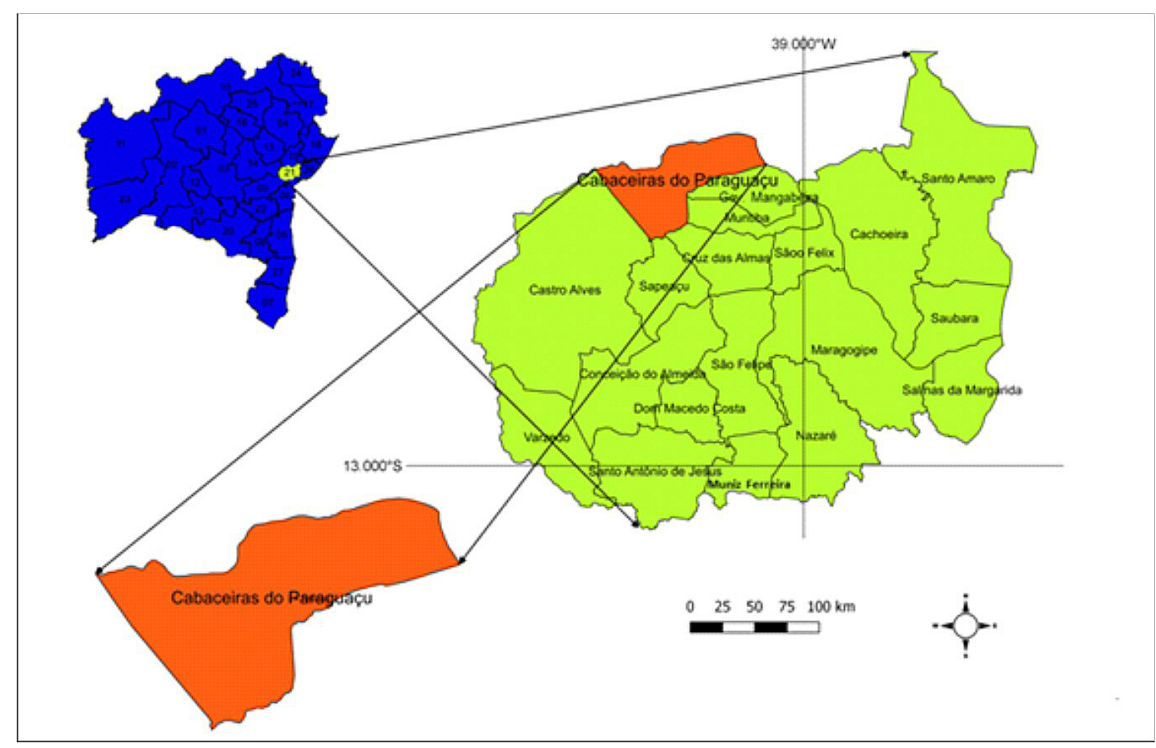

Fonte: http://geocabaceiras.blogspot.com/2017/08/mapa-de-localizacao-de-cabaceiras-do.html

Figura 1 - Imagem do município de Cabaceiras do Paraguaçu/BA, Brasil.

A economia do município é basicamente agrícola, com destaque, na zona rural, para as culturas do fumo, feijão, laranja e mandioca (IBGE, 2016).

\section{Escolha da área de estudo}

O local da pesquisa foi selecionado levando-se em conta uma Unidade Básica de
Saúde (UBS), Posto Nilson Salvador, a qual abrange o atendimento das três comunidades estudadas. Ao todo, são cadastradas 442 famílias, cujas faixas etárias variam entre 15-19 anos para 176 pessoas, de 20-39 anos para 525 pessoas, de 40-49 anos para 186 pessoas, de 50-59 anos para 114 pessoas, e maior que 60 anos para 175 pessoas, totalizando 1.176 pessoas. 


\section{Determinação do tamanho da amostra}

O número de pessoas a serem entrevistadas para representar a população de estudo seguiu as técnicas de amostragem descritas por Tagliacarne (1976). Foram distribuídos 288 questionários entre os moradores das três comunidades com idade entre 18 a 91 anos (homens e mulheres), sendo aplicados 96 questionários para cada comunidade. O número amostral dos informantes com margem de erro de $5 \%$ foi acima de 286 pessoas, visto que há, aproximadamente, 1.146 pessoas residindo nas comunidades onde foi aplicado o estudo.

\section{Aspectos éticos}

Para a realização da pesquisa, o trabalho foi submetido e aprovado pelo Comitê de Ética e Pesquisa da Faculdade Maria Milza, correspondente a CAEE: 47955115.5.0000.5025, sob o protocolo de aprovação 560443, conforme os padrões exigidos pela Resolução CNS 466/12. A coleta dos dados etnobotânicos deu-se por meio de um questionário aplicado nos horários das $8 \mathrm{~h}$ às $12 \mathrm{~h}$ e das $14 \mathrm{~h}$ às $17 \mathrm{~h}$. As abordagens foram realizadas diretamente com os membros das comunidades, em suas referidas residências. Durante a visita aos domicílios, foi explanado, com cada participante, a natureza do trabalho. Ao aceitarem participar da pesquisa, os moradores assinaram duas vias do Termo de Consentimento Livre e Esclarecimento (TCLE), ficando uma cópia com eles e uma com o pesquisador. Realizaram-se perguntas sobre o nome das plantas mais utilizadas, a aquisição, as formas de uso e a parte da planta utilizada; idade, gênero, estado civil, escolaridade e tempo de residência na comunidade.

\section{Coleta de dados}

O estudo constituiu-se em uma pesquisa de natureza qualitativa, de caráter exploratório e descritivo. Apenas 210 pessoas responderam ao questionário, 70 pessoas de cada comunidade, sendo que 78 pessoas se recusaram a participar. Todos os questionários foram analisados de acordo com a literatura pertinente; e os dados, submetidos à estatística descritiva, utilizando-se a frequência relativa (Carvalho et al., 2013), calculada da seguinte forma: FR $=$ NTI $\times 100 / n$ (\%), onde NTI $=\mathrm{n}$ total de informações; $e \mathrm{n}=\mathrm{n}$ de citações/categoria.

\section{A coleta e identificação das espécies}

As plantas citadas foram coletadas junto aos participantes da pesquisa para a devida identificação. A coleta se deu em diversos locais, como: quintais dos domicílios, residências de vizinhos, no campo, em comércio, entre outros. Três amostras representativas ou que apresentassem, no período de coleta, folhas, flores e/ou frutos, foram recolhidas, como também foram feitas anotações sobre o local da coleta. As amostras foram levadas para o Herbário da Universidade Federal do Recôncavo da Bahia, onde as exsicatas foram herborizadas e identificadas.

\section{Resultados e Discussão}

O estudo etnobotânico foi realizado com um total de 210 moradores, sendo entrevistados $70 \mathrm{em}$ cada comunidade escolhida para pesquisa. Dos entrevistados, o gênero feminino prevaleceu nas comunidades, com $76 \%$ em Nova Aparecida, $61 \%$ em Jacarezinho e $5 \%$ em Pé de Serra (Figura 2).

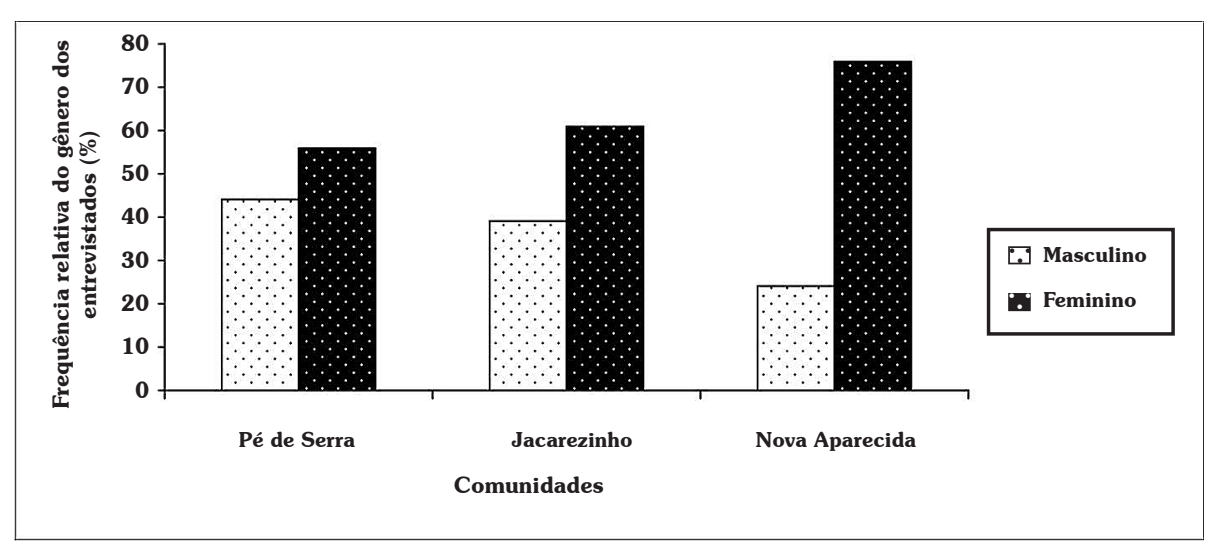

Figura 2 - Frequência relativa do gênero dos entrevistados das comunidades de Nova Aparecida, Jacarezinho e Pé de Serra, no município de Cabaceiras do Paraguaçu/BA, Brasil. 
Em Mimoso, no município de Paulista/PB, constatou-se que $71,42 \%$ dos entrevistados eram do sexo feminino (Bezerra et al., 2012). Em Salobra Grande, no Mato Grosso, o maior número de informantes foi do sexo feminino, apontando que as mulheres em casa realizam as atividades domésticas, enquanto os homens trabalham fora (Souza et al., 2015). As mulheres são responsáveis pelos cuidados domésticos e dos filhos, buscando os conhecimentos sobre plantas medicinais como tratamento caseiro para curar ou prevenir doenças dos integrantes da família (Löbler et al., 2014).

Apenas $25,7 \%$ dos entrvistados de Nova Aparecida e de Pé de Serra possuem segundo grau completo. Em Jacarezinho, apenas 14,3\% possuem segundo grau completo, $17,1 \%$ são apenas alfabetizados e $17,1 \%$ com ensino fundamental I incompleto (Figura 3).

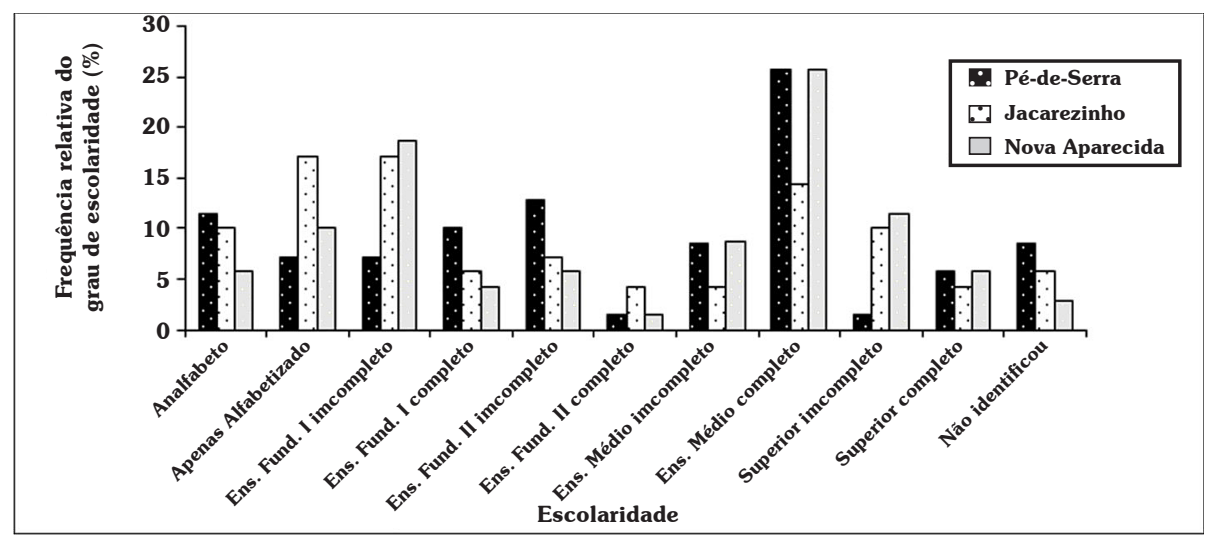

Figura 3 - Frequência relativa do grau de escolaridade dos entrevistados das comunidades de Nova Aparecida, Jacarezinho e Pé de Serra, no município de Cabaceiras do Paraguaçu/BA, Brasil.

As condições socioeconômicas e a baixa escolaridade não influenciam no conhecimento sobre as plantas medicinais, pois as tradições familiares e culturais geralmente são transmitidas de geração a geração (Souza et al., 2015). O baixo nível de escolaridade não influencia o conhecimento sobre as plantas medicinais (Araújo et al., 2015). A baixa escolaridade se relaciona à participação dos moradores nos trabalhos agrícolas, o que inviabiliza a continuidade dos estudos (Oliveira \& Menini Neto, 2012).

Com relação ao tempo de moradia nas comunidades, $50 \%$ dos entrevistados de Nova Aparecida e $32,8 \%$ da comunidade de Jacarezinho residiam entre 10 a 30 anos naquela comunidade. Porém, $44,2 \%$ dos entrevistados da comunidade de Pé de Serra residiam recentemente, entre 0 a 2 anos na comunidade em estudo (Figura 4).

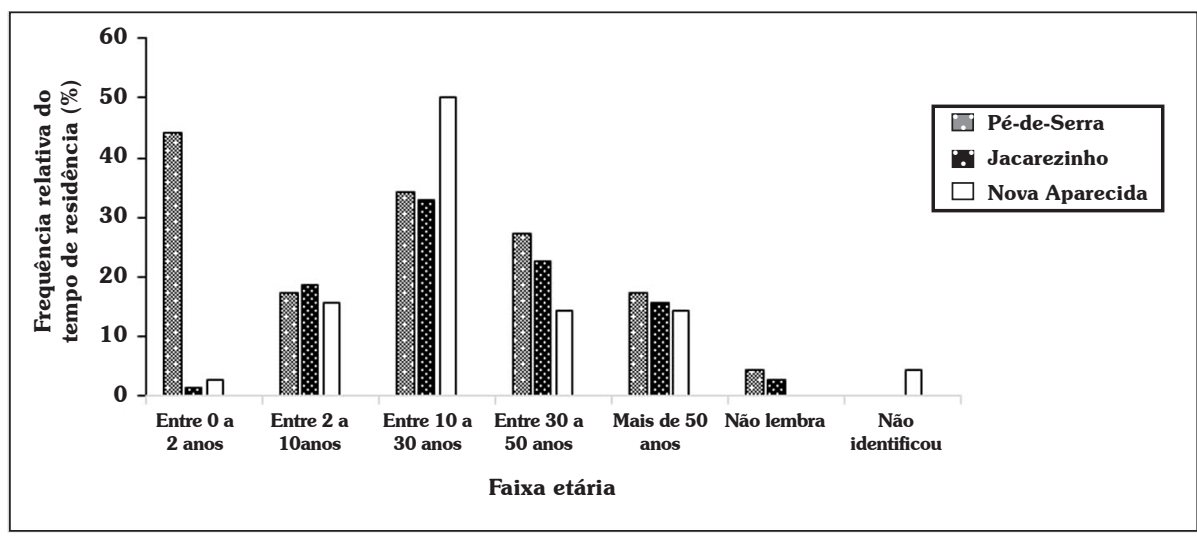

Figura 4 - Frequência relativa do tempo de residência dos entrevistados da comunidade de Nova Aparecida, Jacarezinho e Pé de Serra, no município de Cabaceiras do Paraguaçu/BA, Brasil. 
Em Várzea Grande, $50 \%$ dos participantes da pesquisa residiam há cerca de dez anos ou mais na cidade, construindo conhecimentos populares durante o período de residência no local (David et al., 2014). Situação também identificada por Leite et al. (2015), em que $30 \%$ dos informantes residiam há mais de 30 anos na localidade apresentam maior conhecimento sobre o uso das plantas medicinais.

Considerando o estado civil dos moradores, a condição de casado se destaca em relação às demais (Figura 5), com 47,2\% em Nova Aparecida, 48,6\% em Jacarezinho, e 52,9\% em Pé de Serra.

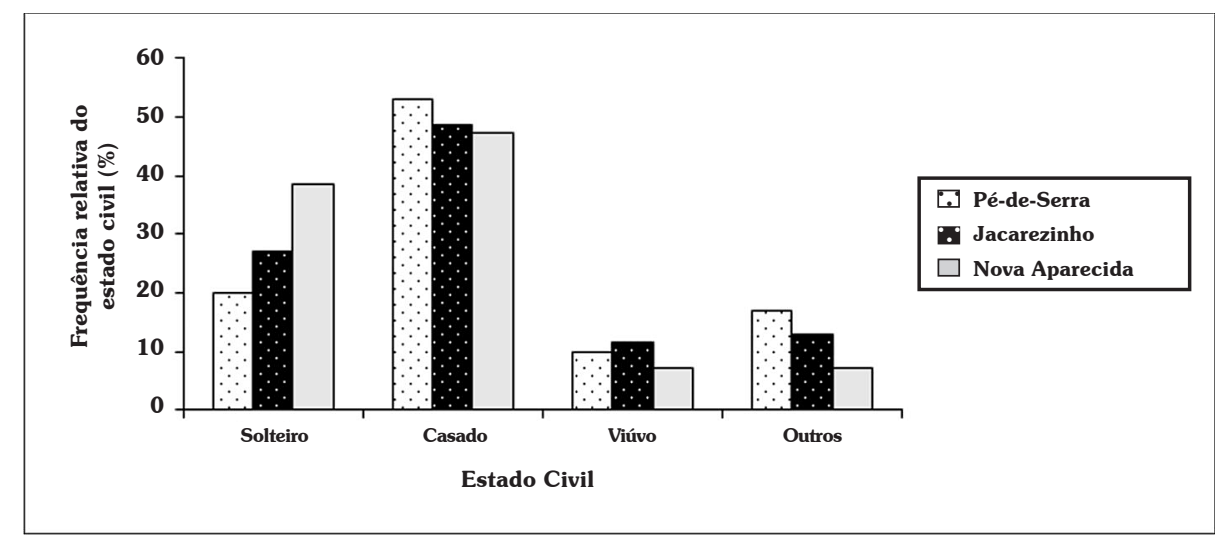

Figura 5 - Frequência relativa do estado civil dos entrevistados da comunidade de Nova Aparecida, Jacarezinho e Pé de Serra, no município de Cabaceiras do Paraguaçu/BA, Brasil.

De acordo com Freitas et al. (2011), 80\% dos entrevistados eram casados e tinham filhos, $e$ essa condição relaciona-se com o maior conhecimento sobre as plantas medicinais. A existência dos filhos implica o uso de soluções práticas e imediatas para o tratamento de doenças (Silva, 2014; Ferreira et al., 2014).

A utilização de plantas medicinais como medicamento se dá em $64,3 \%$ de Nova Aparecida; 71,5\% em Jacarezinho; e 61,5\% em Pé de Serra (Figura 6).

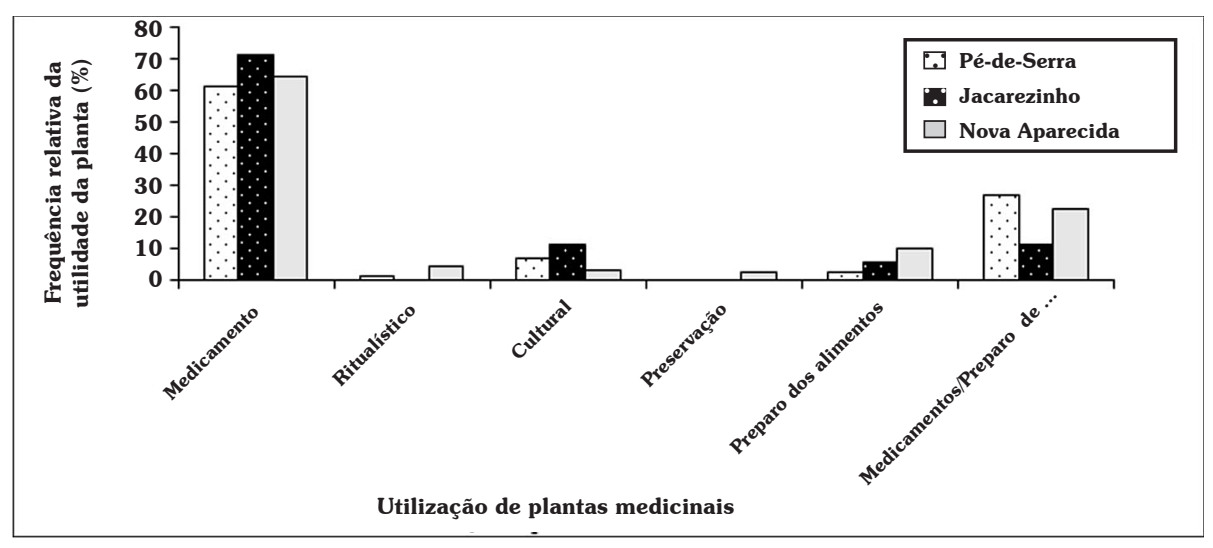

Figura 6 - Frequência relativa das utilidades das plantas medicinais pelos entrevistados das comunidades de Nova Aparecida, Jacarezinho e Pé de Serra, no município de Cabaceiras do Paraguaçu/BA, Brasil. 
$\mathrm{Na}$ comunidade indígena Potiguaras, da aldeia São Francisco, no litoral norte da Paraíba, $36,7 \%$ dos entrevistados só utilizava as plantas medicinais como remédio, $40 \%$ para rezar e $20 \%$ para fins ritualísticos, mostrando que a cultura de cada povo interfere na forma de uso das ervas medicinais (Vasconcelos \& Cunha, 2013). O uso das plantas medicinais como medicamento pode ser explicado pela dificuldade em receber assistência médica e pelo alto custo dos medicamentos sintéticos (Nascimento Júnior et al., 2015).

Nas comunidades de Nova Aparecida, $58,6 \%$, de Jacarezinho $57,2 \%$ e Pé de Serra $44,3 \%$ dos entrevistados obtiveram seus conhecimentos sobre as plantas medicinais através de seus pais (Figura 7).

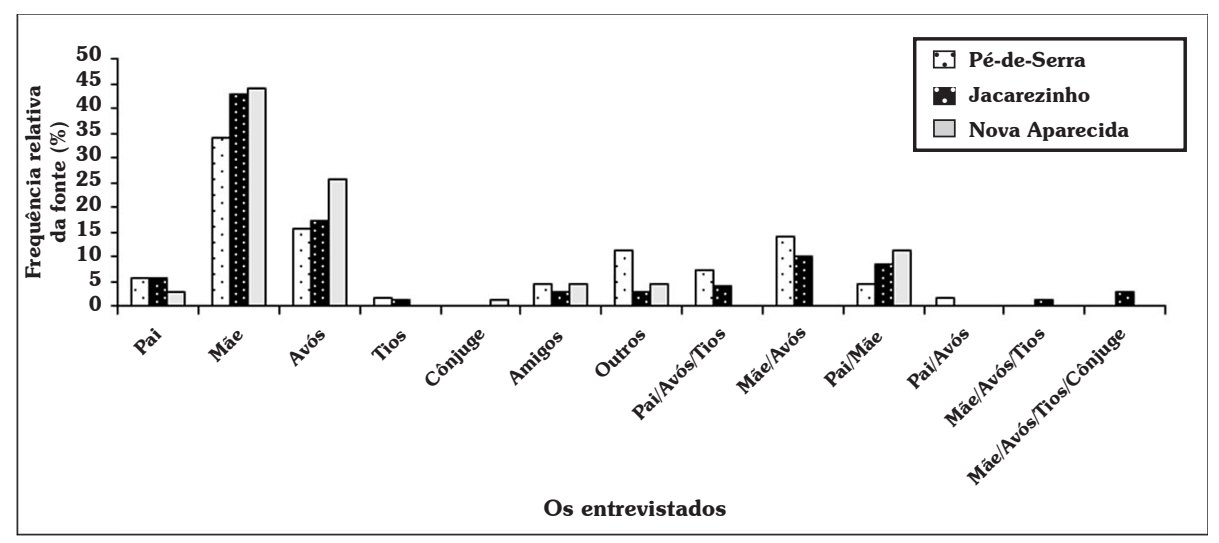

Figura 7 - Frequência relativa da fonte de conhecimento sobre plantas medicinais adquirido pelos entrevistados nas comunidades de Nova Aparecida, Jacarezinho e Pé de Serra, no município de Cabaceiras do Paraguaçu/BA, Brasil.

A transmissão dos conhecimentos sobre as plantas medicinais é proveniente dos pais e/ou avós. A tradição familiar é a razão pela qual os indivíduos mais utilizam as plantas medicinais, pois os pais passam para seus filhos os costumes e ensinamentos (Siqueira \& Pereira, 2014). O contato familiar evidencia a importância da família na transmissão do conhecimento através da oralidade (Motta et al., 2016).
Sobre a eficácia das plantas medicinais em relação aos medicamentos sintéticos, $72,9 \%$ dos informantes das comunidades de Nova Aparecida, 75,7\% de Jacarezinho e 72,9\% de Pé de Serra confirmaram ter efeito moderado na sua eficácia, comparado ao uso dos fármacos sintéticos (Figura 8).

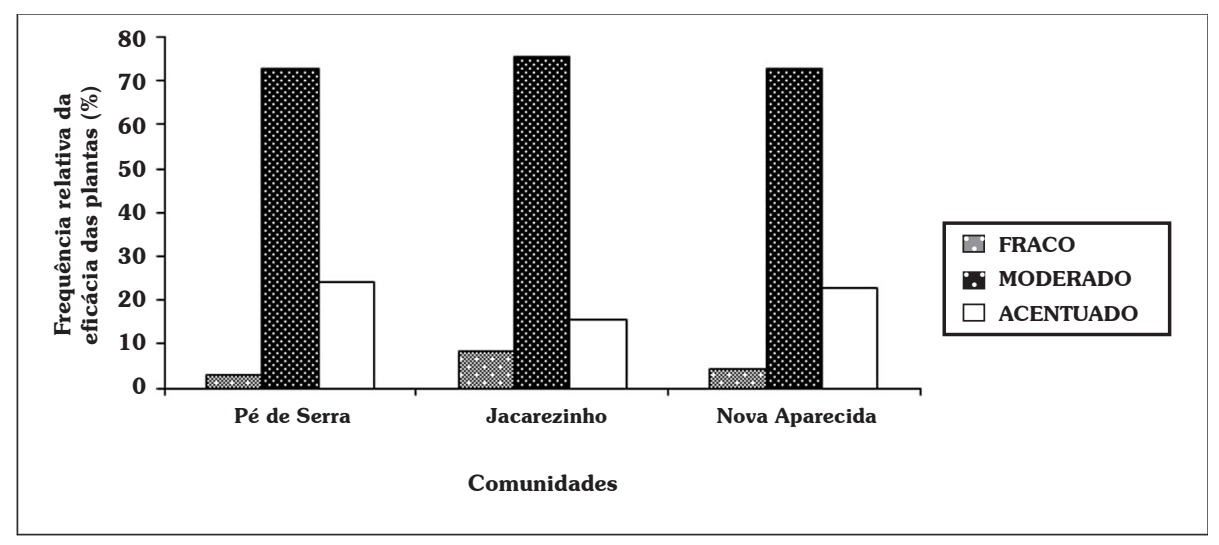

Figura 8 - Frequência relativa da eficácia das plantas medicinais, em relação aos medicamentos de farmácia, nas comunidades de Nova Aparecida, Jacarezinho e Pé de Serra, no município de Cabaceiras do Paraguaçu/BA, Brasil. 
Na comunidade da Várzea, mais de $90 \%$ dos entrevistados informaram que o tratamento com ervas é bastante comum, com resultados satisfatórios, e outros acreditam não fazer mal à saúde (Oliveira \& Menini Neto, 2012). Estudos farmacológicos que comprovem a eficácia terapêutica das espécies são importantes para a segurança do seu uso (Carvalho et al., 2013).

$\mathrm{O}$ estudo identificou que as folhas são as partes mais utilizadas da planta pelos $72,9 \%$ moradores de Nova Aparecida, $35,7 \%$ de Jacarezinho e $34,2 \%$ de Pé de Serra (Figura 9).

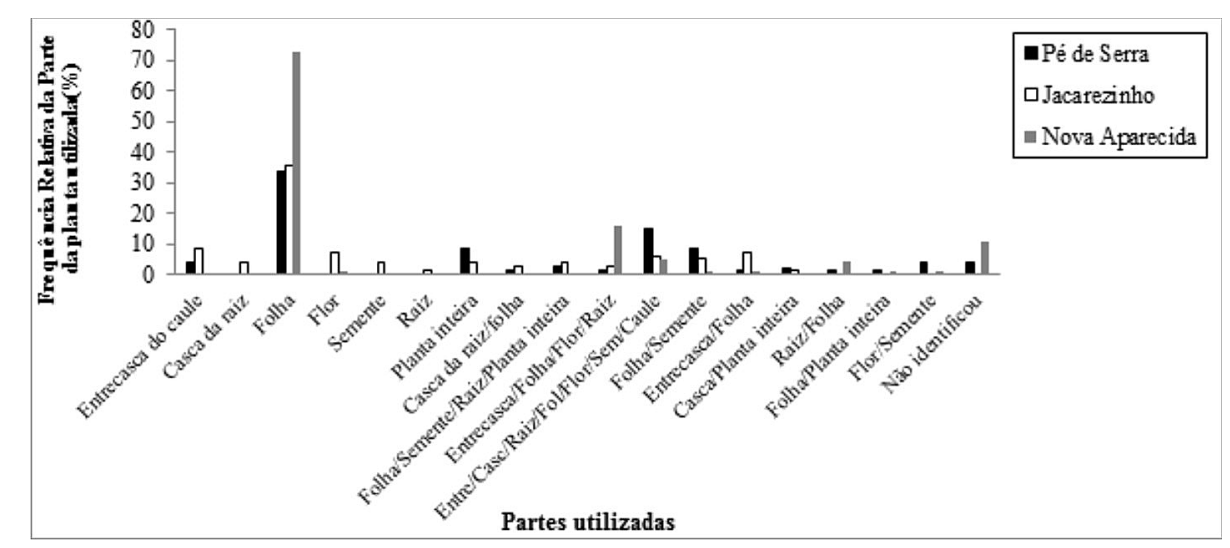

Figura 9 - Frequência relativa da parte da planta medicinal mais utilizada pelos informantes das comunidades Nova Aparecida, Jacarezinho e Pé de Serra, no município de Cabaceiras do Paraguaçu/BA, Brasil.

O uso das folhas para fins medicinais foi observado em $68,2 \%$ dos casos estudados na medicina caseira local (Meyer et al., 2012). As folhas são as partes mais citadas, por sua disponibilidade na planta durante a maior parte do ano, e por apresentarem princípios ativos $e$ terapêuticos que curam enfermidades comuns na população brasileira (Guerra et al., 2012; Silva et al., 2015).

O uso do chá ou infusão aparece no estudo com 59,2\% na comunidade de Nova Aparecida, 47,1\% na de Jacarezinho e $40 \%$ na de Pé de Serra, das 47 espécies citadas com medicinais pelos moradores (Figura 10).

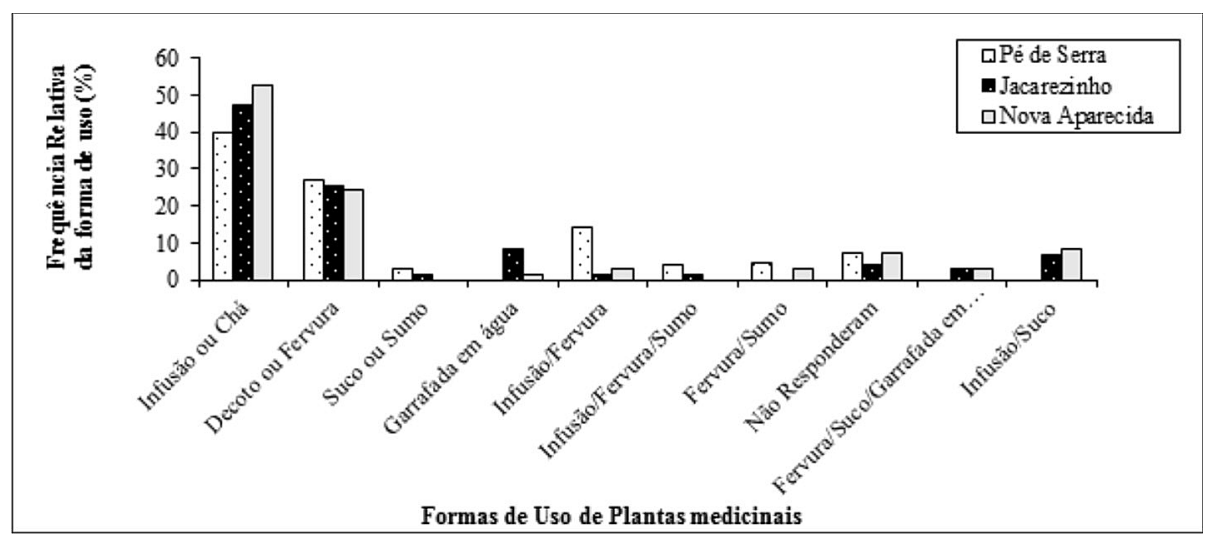

Figura 10 - Frequência relativa da forma de utilização das plantas medicinais nas comunidades de Nova Aparecida, Jacarezinho e Pé de Serra, no município de Cabaceiras do Paraguaçu/BA, Brasil. 
Os chás podem ser preparados de diferentes modos, dependendo da parte da planta a ser utilizada. É a forma de uso mais comum entre a população brasileira, devido à facilidade $e$ transmissão do preparo. Na maioria das vezes, o preparo é obtido através do uso das folhas das plantas (Carvalho et al., 2013). Outra forma é a infusão, recomendada quando se utilizam as partes mais tenras das plantas, como as folhas (Silva et al., 2015), porque a maioria dos remédios caseiros e sintéticos são preparados a partir das folhas, em decorrência da facilidade de obtenção e preparo (Leite et al., 2015).

Neste estudo, em relação à forma de aquisição das plantas, 59,2\% dos entrevistados da comunidade de Nova Aparecida, 47,1\% de Jacarezinho e $40 \%$ de Pé de Serra adquirem as plantas medicinais nos quintais das suas próprias residências (Figura 11).

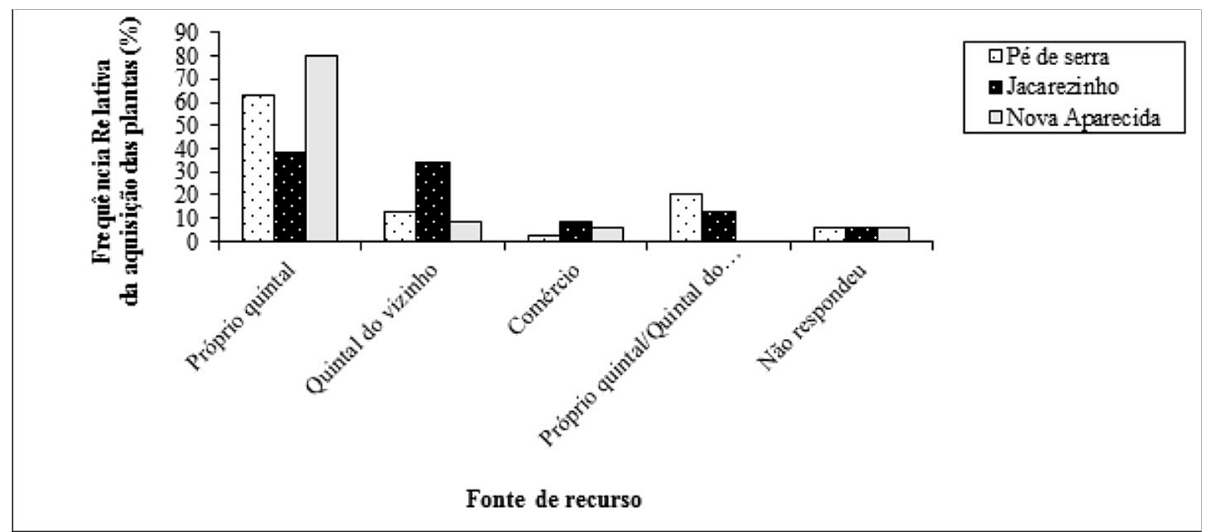

Figura 11 - Frequência relativa da aquisição das plantas medicinais nas comunidades de Nova Aparecida, Jacarezinho e Pé de Serra, no município de Cabaceiras do Paraguaçu/BA, Brasil.

Estudo etnobotânico identificou que $71 \%$ dos casos que se referem à aquisição das plantas no quintal da própria casa (Carvalho et al., 2013). O principal meio de obtenção das plantas medicinais é a partir de cultivo nos quintais das residências, indicando que o cultivo doméstico é essencial para a preservação das espécies medicinais $e$ transmissão dos conhecimentos etnobotânicos (Silva \& Bündchen, 2010).

Neste estudo, $45,7 \%$ dos entrevistados de Nova Aparecida e $57,1 \%$ de Pé de Serra não fazem uso de plantas medicinais para tratamento de doenças específicas. Porém, $60 \%$ dos entrevistados de Jacarezinho utilizam as plantas medicinais para tratarem algum tipo de doença (Figura 12).

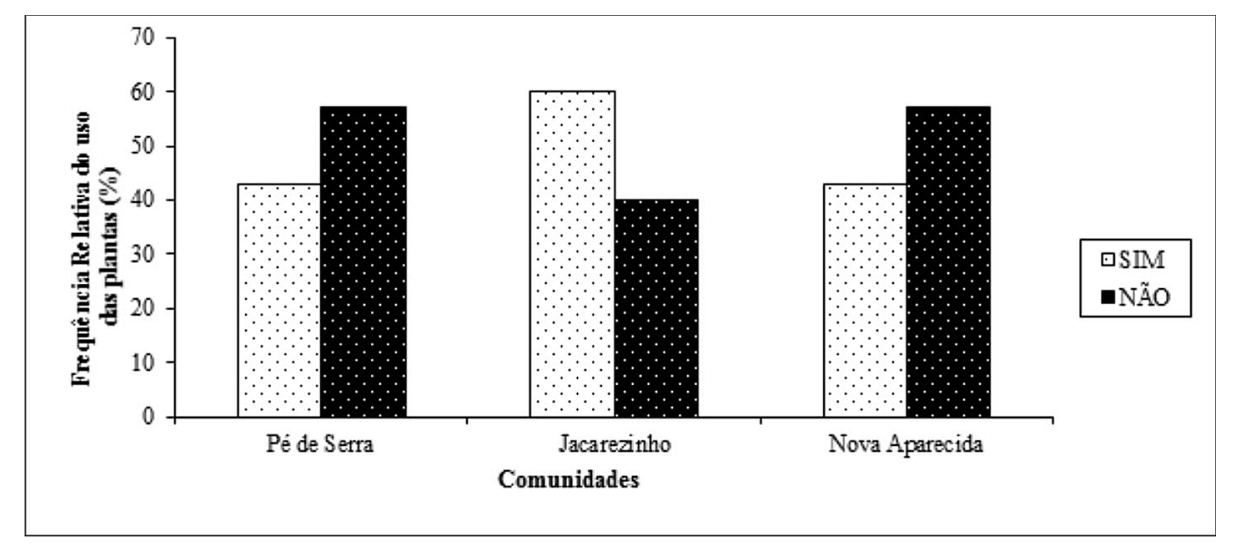

Figura 12 - Frequência relativa da utilização de plantas medicinais para tratamento de doenças específicas nas comunidades de Nova Aparecida, Jacarezinho e Pé de Serra, no município de Cabaceiras do Paraguaçu/BA, Brasil. 
Contribuem coma pesquisa na comunidade de Jacarezinho os resultados apresentados por Maia et al. (2011), em que aproximadamente 90\% das pessoas entrevistadas em Lages e $41 \%$ em Anita Garibaldi utilizam plantas medicinais como recurso natural presente em suas residências; mesmo com tantas outras fontes alternativas de tratamento, seu uso ainda é bastante difundido. Esse recurso é frequentemente encontrado no fundo dos quintais de várias famílias rurais distribuídas em grande parte do país (Silva et al., 2014).
A ação terapêutica das plantas é, para $30,6 \%$ dos entrevistados em Jacarezinho, e $18,4 \%$ em Nova Aparecida, para o tratamento das dores de barriga, e $17 \%$ para o tratamento da gripe em Pé de Serra. A camomila (Chamomilla recutita L.), o boldo (Plectranthus barbatus Andrews) e a aroeira (Schinus Terebinthifolius Radi.) foram citadas para problemas no sistema digestivo; o alho (Allium sativum L.), o sabugueiro (Sambucus australis Cham \& Schldl) e o quioiô (Ocium cf. gratissimum L.), para problemas no sistema respiratório (Figura 13).

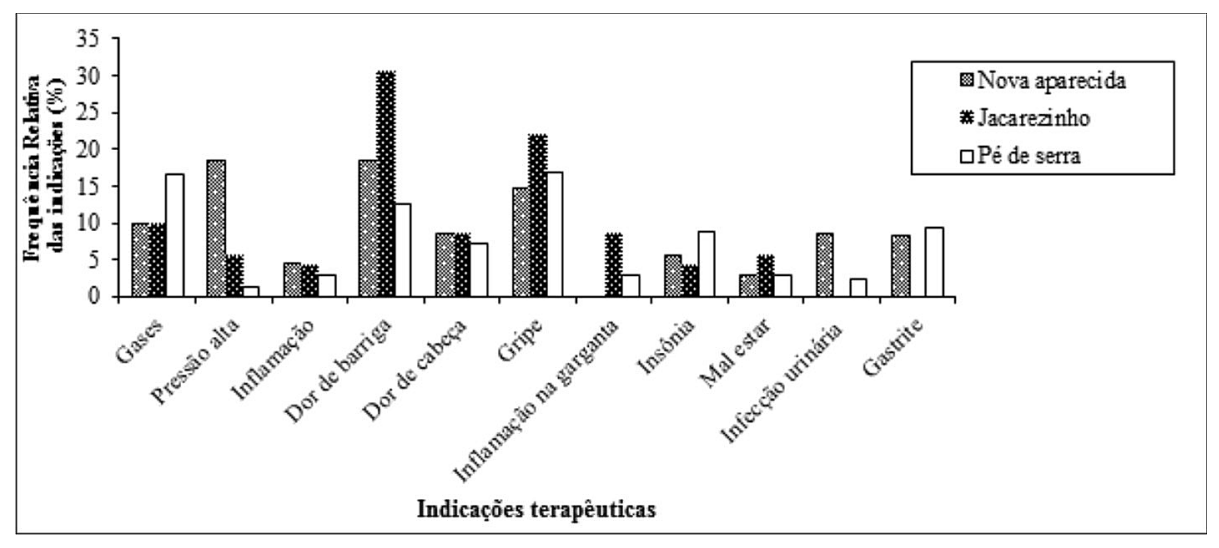

Figura 13 - Frequência relativa das indicações terapêuticas das plantas medicinais citadas pelos entrevistados das comunidades de Nova Aparecida, Jacarezinho e Pé de Serra, no município de Cabaceiras do Paraguaçu/BA, Brasil.

O uso de plantas para tratamento de enfermidades é muito importante, não só para as pessoas da zona rural onde o atendimento médico encontra-se distante, mas também para as pessoas da zona urbana, devido à dificuldade no atendimento médico e ao elevado custo de muitos medicamentos sintéticos (David et al., 2014). As plantas medicinais são uma fonte alternativa de tratamento para diversas doenças, principalmente em comunidades mais carentes, porém, as orientações dos profissionais de saúde são necessárias para evitar riscos no agravo da saúde, de maneira eficaz e segura (Paixão et al., 2016).

As plantas identificadas pertencem a 25 famílias botânicas e 45 espécies citadas como medicinais nas três comunidades estudadas. As famílias Lamiaceae e Asteraceae foram as duas famílias botânicas mais representativas no estudo etnobotânico. A família Lamiaceae, representada com 10 espécies etnobotânicas nas comunidades de Pé de Serra, e 9 espécies em Jacarezinho e Nova Aparecida. A família Asteraceae foi representada por 6 espécies etnobotânicas nas comunidades de Pé de Serra, 2 em Jacarezinho e 3 em Nova Aparecida. Observa-se que a maior diversidade de vegetal foi identificada em Pé de Serra, com 39 representantes em 23 famílias botânicas, enquanto Nova Aparecida com 29, e Jacarezinho com 22 representantes distribuídas em 17 famílias botânicas (Tabela 1). 
Tabela 1 - Plantas indicadas para uso medicinal, segundo os entrevistados das comunidades de Nova Aparecida, Jacarezinho e Pé de Serra, no município de Cabaceiras do Paraguaçu/BA, Brasil, 2018.

\begin{tabular}{|c|c|c|c|c|c|}
\hline \multirow[b]{2}{*}{ Famílias/Espécies } & \multirow[b]{2}{*}{ Nome popular } & \multirow{2}{*}{$\begin{array}{l}\text { Hábito de } \\
\text { crescimento }\end{array}$} & \multicolumn{3}{|c|}{ Número de citações/Comunidade } \\
\hline & & & Pé de Serra & Jacarezinho & $\begin{array}{c}\text { Nova } \\
\text { Aparecida }\end{array}$ \\
\hline \multicolumn{6}{|l|}{ Adoxaceae } \\
\hline Sambucus australis Cham \& Schldl & Sabugueiro & Arbusto & 10 & 1 & 1 \\
\hline \multicolumn{6}{|l|}{ Alliaceae } \\
\hline Allium cepa $\mathrm{L}$. & Cebola & Raiz & 13 & 0 & 10 \\
\hline Allium sativum L. & Alho & Raiz & 17 & 1 & 11 \\
\hline \multicolumn{6}{|l|}{ Amaranthaceae } \\
\hline Schinus Terebinthifolius Radi. & Aroeira & Árvore & 3 & 1 & 4 \\
\hline \multicolumn{6}{|l|}{ Anacardiaceae } \\
\hline Anacardium occidentale $\mathrm{L}$. & Cajueiro branco & Árvore & 3 & 0 & 0 \\
\hline \multicolumn{6}{|l|}{ Apiaceae } \\
\hline Foeniculum vulgare Mill & Erva doce & Erva & 29 & 21 & 34 \\
\hline Coriandrum sativum $\mathrm{L}$. & Coentro & Erva & 5 & 0 & 0 \\
\hline \multicolumn{6}{|l|}{ Asteraceae } \\
\hline Artemisia absinthium L. & Losana & Erva & 1 & 1 & 0 \\
\hline Vernonia condensata Baker & Alumã & Subarbusto & 7 & 2 & 2 \\
\hline Baccharis crispa Spreng & Carqueija & Erva & 1 & 0 & 0 \\
\hline Bidens pilosa L. & Picão & Erva & 5 & 0 & 3 \\
\hline Mikania parviflora (Aubl.) H. Karst. & Guaco & Trepadeira & 1 & 0 & 0 \\
\hline Chamomilla recutita $\mathrm{L}$. & Camomila & Erva & 4 & 0 & 5 \\
\hline \multicolumn{6}{|l|}{ Cactaceae } \\
\hline Cereus jamacaru DC. & Mandacaru & Árvore & 0 & 0 & 3 \\
\hline \multicolumn{6}{|l|}{ Celastraceae } \\
\hline Maytenus ilicifolia Schrad. Planch & Espinheira santa & Arbusto & 3 & 0 & 0 \\
\hline \multicolumn{6}{|l|}{ Crassulaceae } \\
\hline Kkalanchoe pinnata (Lam.) Pers. & Folha da costa & Erva & 1 & 1 & 0 \\
\hline \multicolumn{6}{|l|}{ Cucurbitaceae } \\
\hline Marmodica charantia L. & Melão de São Caetano & Trepadeira & 3 & 0 & 0 \\
\hline \multicolumn{6}{|l|}{ Euphorbiacae } \\
\hline Phyllanthus niruri L. & Quebra pedra & Erva & 2 & 0 & 5 \\
\hline \multicolumn{6}{|l|}{ Fabaceae } \\
\hline Stryphnodendron adstringens Vell. & Barbatimão & Árvore & 1 & 1 & 1 \\
\hline \multicolumn{6}{|l|}{ Lamiaceae } \\
\hline Mentha spicata L. & Hortelã & Erva & 6 & 13 & 18 \\
\hline Ocium cf. gratissimum L. & Quioiô & Arbusto & 16 & 4 & 14 \\
\hline Melissa officinalis L. & Melissa & Erva & 16 & 3 & 11 \\
\hline Mentha sp. & Hortelã de cheiro & Erva & 2 & 5 & 5 \\
\hline Mentha pulegium $\mathrm{L}$. & Poejo & Erva & 7 & 2 & 0 \\
\hline
\end{tabular}




\begin{tabular}{|c|c|c|c|c|c|}
\hline \multirow[b]{2}{*}{ Famílias/Espécies } & \multirow[b]{2}{*}{ Nome popular } & \multirow{2}{*}{$\begin{array}{l}\text { Hábito de } \\
\text { crescimento }\end{array}$} & \multicolumn{3}{|c|}{ Número de citações/Comunidade } \\
\hline & & & Pé de Serra & Jacarezinho & $\begin{array}{c}\text { Nova } \\
\text { Aparecida }\end{array}$ \\
\hline \multicolumn{6}{|l|}{ Lamiaceae (Continuação) } \\
\hline Ocimum gratissimum L. & Alfavaca & Erva & 10 & 4 & 1 \\
\hline Ocimum basilicum L. & Manjericão & Erva & 1 & 2 & 7 \\
\hline Plectranthus barbatus Andrews & Boldo & Arbusto & 28 & 0 & 38 \\
\hline Plectranthus amboinicus (Lour). Spreng & Hortelã grosso & Erva & 4 & 1 & 9 \\
\hline Rosmarinus officinalis L. & Alecrim & Subarbusto & 3 & 4 & 7 \\
\hline \multicolumn{6}{|l|}{ Lauraceae } \\
\hline Cinnamomum zeylanicum Blume. & Canela & Árvore & 0 & 0 & 3 \\
\hline Persea americana Mill & Abacate & Árvore & 0 & 1 & 4 \\
\hline \multicolumn{6}{|l|}{ Liliaceae } \\
\hline Laurus nobilis L. & Louro & Árvore & 1 & 0 & 1 \\
\hline Aloe vera $\mathrm{L}$. & Babosa & Erva & 1 & 1 & 0 \\
\hline \multicolumn{6}{|l|}{ Malvaceae } \\
\hline Gossypium hirsutum L. & Algodão & Subarbusto & 3 & 0 & 0 \\
\hline \multicolumn{6}{|l|}{ Myristicacea } \\
\hline Virola surinamensis Rol. Ex Rottb & Noz Moscada & Árvore & 1 & 0 & 0 \\
\hline \multicolumn{6}{|l|}{ Myrtaceae } \\
\hline Eugenia uniflora L. & Pitanga & Árvore & 4 & 0 & 6 \\
\hline Syzyguim aromaticum L. & Cravo & Árvore & 1 & 0 & 1 \\
\hline \multicolumn{6}{|l|}{ Plantaginaceae } \\
\hline Piper umbellatum L. & Tanchagem & Erva & 0 & 1 & 0 \\
\hline \multicolumn{6}{|l|}{ Poaceae } \\
\hline Cymbopogon citratus Stapf. & Capim Santo & Erva & 36 & 19 & 50 \\
\hline \multicolumn{6}{|l|}{ Punicaceae } \\
\hline Punica granatum L. & Romã & Árvore & 2 & 0 & 1 \\
\hline \multicolumn{6}{|l|}{ Rutaceae } \\
\hline Citrus aurantium L. & Laranja & Arbusto & 1 & 1 & 1 \\
\hline Citrus limon L. & Limão & Arbusto & 1 & 0 & 0 \\
\hline \multicolumn{6}{|l|}{ Solanaceae } \\
\hline Solanum paniculatum L. & Jurubeba & Arbusto & 1 & 1 & 1 \\
\hline \multicolumn{6}{|l|}{ Verbenaceae } \\
\hline Lippia alba L & Erva cidreira & Subarbusto & 35 & 19 & 48 \\
\hline \multicolumn{6}{|l|}{ Zingiberaceae } \\
\hline Alpinia mutans Rose & Água-de-Levante & Erva & 1 & 0 & 0 \\
\hline
\end{tabular}

Fonte: Dados coletados durante a pesquisa, 2018. 
Corroboram com os resultados a pesquisa de Oliveira \& Menini Neto (2012), que citam as famílias Asteraceae e Lamiaceae como as mais representativas em Manejo, Lima Duarte/MG, em função de serem famílias cosmopolitas, com espécie de ampla adaptação, tanto em ambientes tropicais quanto temperados. As espécies da família Lamiaceae mais citadas em Pé de Serra são utilizadas como paliativos aos agravos da saúde (Ocium cf. grantissimum L., Melissa officinalis L. e Plectranthus barbatus Andrews); em Jacarezinho, como condimentos ou como ingredientes na preparação de refeições (Mentha spicata L.); e em Nova Aparecida, na produção de chás ou ainda para usos medicinais (Plectranthus barbatus Andrews; M. officinalis L.; Mentha spicata L. e O. cf. grantissimum L.) (Tabela 1).

As espécies dessa família, em sua maioria, são plantas aromáticas, das quais é possível extrair óleos essenciais. Estes possuem uma composição complexa, em uma mistura de hidrocarbonetos, compostos carbonílicos e álcoois, conferindo à família Lamiaceae propriedades de grande utilidade na área da saúde (Gabriel Net \& Gomes, 2018). Em decorrência disso, várias espécies são utilizadas na formulação de medicamentos sintéticos, como as do gênero Mentha (Malaquias et al., 2012).

A família Lamiaceae foi a mais representativa em número de espécies utilizadas como medicinais; $e$ as espécies mais citadas foram o capim santo, a erva cidreira, o boldo e a hortelã (Tabela 1). Para Freitas et al. (2011), a família Lamiaceae apresentou o maior número de etnoespécies (cinco), sendo representada por alecrim (R. officinalis L.), boldo (P. barbatus Andr.), malvarisca ( $P$. amboinicus Lour.), manjericão (O. basilicum L.) e hortelã (M. arvensis L.) e, em seguida, as famílias Anacardiaceae e Rutaceae, ambas com quatro etnoespécies.

As plantas são adquiridas principalmente nos quintais de casa, utilizadas basicamente na forma de chá com o uso das folhas (Carvalho et al., 2013). A importância relativa de algumas plantas em comunidades rurais decorre de sua aplicabilidade no tratamento de diversos tipos de doenças e/ou sintomas em uma comunidade. Porém, pode acontecer de as propriedades das mesmas plantas serem desconhecidas em outras comunidades (Ribeiro et al., 2014). A erva cidreira e o hortelã tiveram maior número de citações, pois são de fácil cultivo devido ao seu pequeno porte, o que facilita o uso como condimento ou na preparação de refeições, na produção de chás ou ainda para usos medicinais, como, por exemplo, no alívio a dores de estômago ou tosse, dentre outros usos. Consequentemente, esses recursos e suas propriedades medicinais se tornam mais familiares às pessoas, pois a maioria é cultivada no próprio quintal de casa, havendo a preocupação em manter os exemplares, no caso de necessidade de uso (David et al., 2014; Paixão et al., 2016).

As espécies da família Asteraceae mais citadas em Pé de Serra são utilizadas na redução da atividade inflamatória e calmante (Bidens pilosa L., Vernonia condensata Baker, Chamomilla recutita L.); em Jacarezinho, para problemas estomacais ( $V$. condensata Baker); e, em Nova Aparecida, as espécies B. pilosa L., $V$. condensata Baker e $C$. recutita $L$. são usadas para facilitar a eliminação de gases, combater cólicas, estimular o apetite e problemas inflamatórios. As espécies mais citadas nas comunidades foram: erva cidreira (Lippia alba L.), capim santo (Cymbopogon citratus Stapf.), erva doce (Foeniculum vulgare Mill), boldo (Plectranthus barbatus Andrews) e hortelã (Mentha spicata L.) (Tabela 1).

A ampla distribuição também indica ser um dos fatores pelo qual a família Asteraceae foi bastante citada. Os gêneros dessa família geralmente apresentam espécies de pequeno porte que têm bom desenvolvimento em todos os tipos de habitat, principalmente em regiões tropicais da América do Sul (Freitas et al., 2011). Algumas espécies da família Asteraceae podem se tornar tóxicas quando ingeridas em grandes concentrações (B. pilosa L. e a $V$. condensata Baker). Porém, cabe ressaltar que a toxicidade de uma planta depende da forma de administração, da mistura e da frequência de uso. Além disso, a falta de padronização ou o desconhecimento da dosagem no preparo com plantas medicinais pode reduzir a eficácia ou até mesmo ser fonte de reações adversas, ocasionado pelo mal uso (Oliverira \& Menini Neto, 2012).

A presença marcante do homem no meio ambiente acompanha a degradação ambiental $e$ a inserção de novos elementos culturais nas comunidades tradicionais, e ameaça muito de perto um acervo de conhecimentos empíricos e um patrimônio genético de valor inestimável para as gerações futuras (Hoeffel et al., 2011). Além disso, tanto o aumento da pressão ecológica exercida 
sobre esses recursos naturais, o valor econômico, o extrativismo predatório, quanto o comércio local, além da degradação ambiental dos ambientes naturais, colocam em risco a sobrevivência de muitas espécies medicinais (Roque et al., 2010). A proximidade das comunidades com o centro do município pode acarretar na menor diversidade vegetal, o que explica o menor número de espécies de porte arbóreo, arbustivo e subarbustos nas comunidades de Jacarezinho e Nova Aparecida. Porém, não foi observado na comunidade de Pé de Serra, que apresentou maior diversidade vegetal.

A maior parte dos recursos biológicos utilizados para tratamento da saúde nos sistemas médicos tradicionais é obtida a partir de vegetais, inteiros ou fragmentados. O conjunto de plantas medicinais que fazem parte desse processo em uma determinada cultura é o resultado de um longo período de validação de sua ação farmacológica (Araujo et al., 2015). Sendo assim, é importante preservar as espécies medicinais utilizadas nas comunidades rurais estudadas, visto que, dentre as 45 espécies citadas, apenas 15 delas estão cadastradas na lista do RENISUS. Ressalta-se também a importância do resgate das informações sobre as plantas utilizadas pelas comunidades, pois o conhecimento tradicional, direcionado às plantas medicinais, pode contribuir para a manutenção da relação entre as pessoas e a natureza, assim como para o manejo dos recursos naturais e a descoberta de plantas-alvo para investigações farmacológicas (Aguiar \& Barros, 2012; Battisti et al., 2013).

\section{Considerações Finais}

A realização desta pesquisa permitiu demonstrar que a maioria dos moradores das comunidades estudadas são mulheres casadas, com conhecimento etnobotânico, que usam as folhas das plantas medicinais na forma de infusão ou chá em sua maior parte, por acreditarem que essas agem de forma moderada no controle ou cura das enfermidades. São pessoas de baixa escolaridade, residentes há dez ou mais anos naquela localidade, e que recebem os conhecimentos sobre as plantas medicinais através dos pais, como forma de preservar a sua cultura.

Assim, ficou evidente a importância da realização de estudos etnobotânicos como uma forma de resgatar e evitar a perda dos saberes tradicionais das comunidades de Jacarezinho, Nova Aparecida e Pé de Serra, e a conservação de espécies medicinais da flora da região.

\section{Referências}

Aguiar LCGG \& Barros, RFM. Plantas medicinais cultivadas em quintais de comunidades rurais no domínio do cerrado piauiense (Município de Demerval Lobão, Piauí, Brasil). Revista Brasileira de Plantas Medicinais, 14 (3): 419-434.

Araújo IFS, Souza LF, Guarçoni EAE \& Firmino WCA. O comércio de plantas com propriedades medicinais na cidade de Bacabal, Maranhão, Brasil, Natureza on line, 13(3): 111-116, 2015.

Battisti C, Garlet TMB, Essi L, Horbach RK, Andrade A \& Badke MR. Plantas medicinais utilizadas no município de Palmeiras das Missões, RS, Brasil. Revista Brasileira de Biociências, 11(3): 338-348, 2013.

Bezerra AMF, Bezerra KKS, Sousa LCFS, Sousa JS \& Borg MGB. Plantas medicinais utilizadas pela comunidade de mimoso no município de Paulista, Paraíba - Brasil. Revista Verde, 7(5): 06-11, 2012.

Brasil. RDC n ${ }^{\circ} 10$ de março de 2010. Dispóe sobre a fitoterapia de drogas vegetais junto à Agência Nacional de Vigilância Sanitária, de 10 de março de 2010.

Carneiro FM, Silva MJP, Borges LL, Albernaz LC \& Costa JDP. Tendências dos estudos com Plantas Medicinais no Brasil. Revista Sapiência, 3(2): 44-75, 2014.

Carvalho JSB, Martins JDL, Mendonça MCS \& Lima LD. Uso popular das plantas medicinais na comunidade da Várzea. Revista de Biologia e Ciências da Terra, 13(2): 58-65, 2013.

Cavalcante ACP \& Silva AG. Levantamento etnobotânico e utilização de plantas medicinais na comunidade Moura, Bananeiras - PB. Revista Monografias Ambientais - REMOA, 14 (2): 3225-3230, 2014.

David M, Mamede JS, Dias GS \& Pasa MC. Uso de plantas medicinais em comunidade escolar de Várzea Grande, Mato Grosso, Brasil. Biodiversidade, 13(1): 38-50, 2014.

Do Ó KDS, Silva GH \& Leite IA. Estudo etnobotânico de plantas medicinais em duas comunidades no estado da Paraíba. Brasil. Biodiversidade, 15(2): 53-61, 2016.

Ferreira FMC, Lourenço FJC \& Baliza DP. Levantamento etnobotânico de plantas medicinais na comunidade quilombola Carreiros, Mercês-Minas Gerais. Revista Verde de Agroecologia e Desenvolvimento Sustentável, 9(3): 205-212, 2014. 
Franco F, Lamano-Ferreira APN \& Ferreira ML. Etnobotânica: aspectos históricos e aplicativos desta ciência. Caderno de Cultura e Ciência, 10(2): 17-23, 2011.

Freitas AVL, Coelho MFB, Maia SSS \& Azevedo RAB. Plantas medicinais: um estudo etnobotânico nos quintais do Sítio Cruz, São Miguel, Rio Grande do Norte, Brasil. Revista Brasileira de Biociências, 10(1): 48-59, 2011.

Gabriel Neto LA \& Gomes FT. Levantamento etnobotânico de plantas medicinais utilizadas pela população do município de Oliveira Fortes/MG. Perspectivas Online: Biológicas \& Saúde, 8(27): 1-17, 2018.

Guerra NM, Ribeiro JES, Carvalho TKN, Pedrosa KM, Felix LP \& Lucena RF. Usos locais de espécies vegetais nativas em uma comunidade rural no semiárido nordestino (São Mamede, Paraíba, Brasil). Revista de Biologia e Farmácia, Especial: 184-210, 2012.

Hoeffel JLM, Gonçalves NM, Fadini AAB \& Seixas SRC. Conhecimento tradicional e uso de plantas medicinais nas APAS'S Cantareira/SP e Fernão Dias/MG. Revista Vitas, 1(2): 1-7, 2011.

IBGE. Censo demográfico, Cabaceiras do Paraguaçu, BA. <htpps//cidades.ibge.gov.br. 2016>. (Acesso em 20/07/ 2019).

Leite IA, Morais AM, Do Ó KDS, Carneiro RG \& Leite CA. A etnobotânica de plantas medicinais no município de São José de Espinharas, Paraîba, Brasil. Biodiversidade, 14(1): 22-30, 2015.

Löbler L, Santos D, Rodrigues ES \& Santos NRZ. Levantamento etnobotânico de plantas medicinais no bairro Três de Outubro, da cidade de São Gabriel, RS, Brasil. Revista Brasileira de Biociências, 12(2): 81-89, 2014.

Malaquias G, Cerqueira GS, Ferreira PMP, Pacheco ACL, Souza JMC, Deus, MSM \& Peron AP. Utilização na medicina popular, potencial terapêutico e toxicidade em nível celular das plantas Rosmarinus officinalis L., Salvia officinalis L. e Mentha piperita L. (Família Lamiaceae). Revista de Toxicologia, Risco Ambiental e Sociedade, v. 7, n. 3, p. 50-68, 2014.

Maia EA, Freancisco J, Pires T \& Manfredi-Coimbra $\mathrm{S}$. O uso de espécies vegetais para fins medicinais por duas comunidades da Serra Catarinense, Santa Catarina, Brasil. Revista de Biologia e Ciências da Terra, 11(1): 54-59, 2011.

Meyer L, Quadros KE \& Zeni ALB. Etnobotânica na comunidade de Santa Bárbara, Ascurra, Santa Catarina, Brasil. Revista Brasileira de Biociências, 10(3): 258-266, 2012.
Motta AO, Lima DCS \& Vale CR. Levantamento do uso de plantas medicinais em um centro de educação infantil em Goiânia-Go. Revista da Universidade Vale do Rio Verde, 14(1): 629-646, 2016.

Muniz RMCC et al. Plantas medicinais da RENISUS de atuação central. Informa, 24(1-3): 75-79, 2012.

Nascimento Júnior BJ, et al. Uso de plantas medicinais no tratamento da estomatite aftosa recorrente na cidade de Petrolina-Pernambuco. Revista Cereus, 7(3): 18-37, 2015.

Oliveira ER \& Menini Neto L. Levantamento etnobotânico de plantas medicinais utilizadas pelos moradores do povoado de Manejo, Lima Duarte/MG. Revista Brasileira de Plantas Medicinais, 14(2): 311-320, 2012.

Paixão JÁ, Conceição RS, Santana Neto AF, Neto JFA \& Santos US. Levantamento bibliográfico de plantas medicinais comercializadas em feiras da Bahia e suas interações medicamentosas. Revista Eletrônica de Farmácia, 13(2): 71-81, 2016.

Ribeiro DA, Macêdo DG, Oliveira LGS, Saraiva MEI, Oliveira SFI, Souza MMAI \& Menezes IRA. Therapeutic potential and use of medicinal plants in na area of the Caatinga in the state of Ceará, northeastern Brazil. Revista Brasileira de Plantas Medicinais, 16(4): 1-10, 2014.

Roque AA, Rocha RM \& Loiola MIB. Uso e diversidade de plantas medicinais da Caatinga na comunidade rural de Laginhas, município de Caicó, Rio Grande do Norte (Nordeste do Brasil). Revista Brasileira de Plantas Medicinais, 12(1): 31-42, 2010.

Scardelato JÁ, Legramandi VHP \& Sacramento LVS. Ocorrência de cristais em plantas medicinais utilizadas no tratamento da nefrolitíase: paradoxo? Revista Brasileira de Farmacognosia, 34(2): 161-168, 2013.

Silva JÁ \& Bündchen M. Conhecimento etnobotânico sobre as plantas medicinais utilizadas pela comunidade do Bairro Cidade Alta, município de Videira, Santa Catarina, Brasil. Unoesc \& CiênciaACBS, 2(2): 129-140, 2010.

Silva MFP. Plantas medicinais: cultivo em quintais pela população de um município do semiárido Piauiense, nordeste do Brasil. Revista Intertox de Toxicologia, Risco Ambiental e Sociedade, 7(3): 101-113, 2014.

Silva PH, Barros MS, Oliveira YR \& Abreu MC. A Etnobotânica e as plantas medicinais sob a perspectiva da valorização do conhecimento tradicional e da conservação ambiental. Revista de Ciências Ambientais, 9(2): 67, 2015.

Siqueira $\mathrm{AB}$ \& Pereira SM. Abordagem etnobotânica no ensino de Biologia. REMEA-Revista Eletrônica do Mestrado em Educação Ambiental, 31(2): 247-260, 2014. 
Souza KA, Botini N, Antoniazzi CA, Chaves CF \& Añez RB. Estudo etnobotânico do falso barbatimão (Dimorphandra mollis Benth, LeguminosaeCaesalpinoideae) na comunidade de Salobra Grande, Porto Estrela, MT. Biodiversidade, 14(2): 106-115, 2015.

Staniski A, Floriani N \& Strachulski J. Estudo etnobotânico de plantas medicinais na comunidade faxinalense Sete Saltos de Baixo, Ponta Grossa-PR. Terra Plural, 8(2): 320-340, 2014.
Strachulski J \& Floriani N. Conhecimento popular sobre plantas: um estudo etnobotânico na comunidade rural de Linha Criciumal, em Cândido de Abreu-PR. Revista Geografar, 8(1): 125-153, 2013.

Tagliacarne G. 1976. Pesquisa de mercado. São Paulo: Atlas, 176p.

Vasconcelos GPSS \& Cunha EVL. Levantamento de plantas medicinais utilizadas por indígenas potiguaras da aldeia São Francisco (Litoral Norte da Paraíba). Gaia Scientia, 7(1): 146-156, 2013.

Biodiversidade Brasileira - BioBrasil.

Fluxo Contínuo

n. 1,2021

http://www.icmbio.gov.br/revistaeletronica/index.php/BioBR

Biodiversidade Brasileira é uma publicação eletrônica científica do Instituto Chico Mendes de

Conservação da Biodiversidade (ICMBio) que tem como objetivo fomentar a discussão e a disseminação de experiências em conservação e manejo, com foco em unidades de conservação e espécies ameaçadas.

ISSN: 2236-2886 